\title{
Traducciones de literatura infantil y juvenil al gallego (1968-1978)
}

\author{
Translations of children's literature into Galician (1968-1978)
}

Mónica Domínguez Pérez

University of Abuja

Department of English and Literary Studies

mdomi249@xtec.cat

[Recibido, setembro 2010; aceptado, outubro 2010]

\section{RESUMEN}

La literatura infantil y juvenil gallega se formó entre 1968 y 1978, gracias a obras autóctonas y a la aportación de las traducciones. En este artículo se presentará una panorámica de la etapa indicada, prestando especial atención a las traducciones del extranjero. Se observará así que las traducciones carecían de planificación, pero resultaban significativas de unas tendencias y contribuyeron a la formación de la literatura infantil y juvenil gallega mediante la introducción de nuevos modelos literarios.

PALABRAS CLAVE: literatura infantil, traducción, historia de la literatura, análisis literario, polisistemas.

Domínguez Pérez, M., (2011): “Traducciones de literatura infantil y juvenil al gallego (1968-1978)”. Madrygal (Madr), 14: 49-57.

\section{RESUMO}

A literatura infantil e xuvenil galega formouse entre 1968 e 1978, grazas a obras autóctonas e á aportación das traducións. Neste artigo presentarase unha panorámica da etapa indicada, prestando especial atención ás traducións do estranxeiro. Observarase así que as traducións carecían de planificación, pero resultaban significativas dunhas tendencias e contribuíron á formación da literatura infantil e xuvenil galega mediante a introdución de novos modelos literarios.

PALABRAS CHAVE: literatura infantil, tradución, historia da literatura, análise literario, polisistemas.

Domínguez Pérez, M., (2011): “Traducións de literatura infantil e xuvenil ao galego (1968-1978)”. Madrygal (Madr.), 14: 49-57.

\begin{abstract}
Galician children's literature was formed between 1968 and 1978, thanks to indigenous works and to the contribution of translations. An overview of the mentioned period will be presented in this article, paying special attention to translations from abroad. It will be observed thus, that translations lacked planning, but pointed to certain tendencies and contributed to the formation of the Galician children's literature through the introduction of new literary models.

KEY WORDS: children's literature, translation, history of literature, literary analysis, polysystems.

Domínguez Pérez, M., (2011): “Translations of children’s literature into Galician (1968-1978)”. Madrygal (Madr), 14: 49-57.
\end{abstract}

SUMARIO: 1. Introducción. 2. Producción. 3. Conclusiones. 4. Bibliografía. 


\section{INTRODUCCIÓN}

En este artículo se presentará la producción de literatura infantil y juvenil (desde ahora LIJ) gallega entre 1968 y 1978, prestando una atención especial a las traducciones del extranjero. El objetivo es observar las tendencias de las traducciones, relacionándolas con las producciones propias y con el desarrollo del sistema de LIJ gallega. Se presentan ya algunas hipótesis: la preferencia por las creaciones autóctonas frente a las traducciones, el predominio de las lenguas prestigiosas del momento (castellano, inglés y francés) como lenguas de partida de las traducciones, y la introducción de nuevos modelos literarios a través de las mismas.

Se seguirá para este trabajo la teoría de los polisistemas (Even-Zohar 1990), que se ha probado tan productiva a la hora de analizar las traducciones y su relación con la literatura de llegada. Se considera, por tanto, que la literatura es una red estructurada de relaciones entre muy diversos elementos, y que las diferentes literaturas se relacionan entre sí a través de las traducciones y otras formas de contacto. De esta manera, la literatura castellana adopta una posición central con respecto a las otras literaturas del ámbito español. La perificidad del polisistema gallego se muestra en aspectos como el bajo número de publicaciones, el retraso en la introducción de nuevos modelos literarios con relación a la literatura castellana, etc. Por ejemplo, la LIJ castellana fue cultivada desde el siglo XIX, mientras que la LIJ gallega comenzó en 1922 y hasta 1967 se publicaron menos de una decena de obras.

El período que nos ocupa, de 1968 a 1978, se sitúa casi por completo en los años de la dictadura de Franco, que al principio prohibía y más tarde recelaba de las publicaciones en gallego. En 1967 estas ya eran permitidas, y por eso se retoma la LIJ con unas pocas traducciones del catalán y el castellano. Aquí no se comentarán porque ya han sido tratadas en trabajos anteriores (Domínguez 2008). En 1968 comienza el período de formación de la LIJ gallega, que podemos cerrar en 1978. A partir de 1979 el desarrollo del sistema será continuo hasta llegar a nuestros días, en que la posición con respecto a la LIJ castellana ya no es tan periférica como lo era durante la etapa estudiada.

\section{PRODUCCIÓN}

Las creaciones propias son las que predominan entre 1968 y 1978. Tras las primeras publicaciones de LIJ en 1967, al año siguiente se presentan cinco obras, pertenecientes a los tres archigéneros clásicos. También se amplía el número de instituciones implicadas en la formación del sistema de LIJ, aunque algunas de ellas no volverán a editar este tipo de literatura. La Caja de Ahorros-Monte de Piedad de La Coruña y Lugo, en cambio, patrocina a lo largo de muchos años el concurso literario "O Facho", cuyos textos premiados eran publicados en ocasiones por Galaxia. Los finalistas aparecían también en el diario La voz de Galicia o en otras publicaciones periódicas. Pero hay que resaltar, sobre todo, que los ganadores del concurso entre 1973 y 1976 fueron editados en un volumen recopilatorio (Martín et al. 1979) que mereció entrar, por primera vez en la historia de la LIJ gallega, en la lista de honor del IBBY (1982). Quiero señalar así que algunas de las creaciones gallegas para la infancia y la juventud de estos años son de calidad reconocida, pero no fueron editadas en libro hasta los últimos años del período. Al mantenerse desconocidas no fueron tampoco traducidas, $\mathrm{y}$ aunque la lista de honor mencionada se confecciona con la finalidad de recomendar obras para su traducción no ocurrió así con el libro gallego. Solo uno de los cuentos fue publicado en catalán varios años después (Moreno 1989), cuando ya la autora era conocida en la LIJ catalana por otras dos obras y en la castellana por tres. Quizá se debe la ausencia de la traducción completa al desconocimiento de la lengua y la literatura gallegas (como consecuencia de su situación periférica), así como al gran aumento y renovación de la LIJ en otras lenguas desde los años 80.

En cuanto a los modelos repertoriales, Fernández Paz (1989: 24) señala que el camino abierto por las primeras traducciones continuaría durante muchos años en la LIJ gallega. En un primer momento, en cambio, parece que la incidencia fue nimia. La debilidad de la industria editorial gallega y la falta de jóvenes lectores en gallego hicieron que ninguno de los libros autóctonos publicados en esta etapa de formación fuera similar a los traducidos previamente del catalán y el castellano (por ejemplo Cots 1966, Candel 1967), ni en el uso de la policromía, ni en la encuadernación en cartoné plastificado, ni en los modelos narrativos ${ }^{1}$. Muchas de las

\footnotetext{
${ }^{1}$ Roig (2006: 33) establece la similitud de formato entre la colección “A Galea de ouro" y Contos pra nenos (Prieto 1968), pero las diferencias son considerables. Por ejemplo, la colección es policromada y encuadernada en cartoné plastificado, mientras que Contos pra
} 
obras publicadas por estos años siguen los esquemas de la literatura oral. Otras veces se trata de obras de frontera entre la LIJ y la literatura para adultos (por ejemplo: Manuel Ma Fernández 1989, Marín 1978), ya que la delimitación entre una y otra era aún muy difusa. Las innovaciones propuestas por estos años pueden deberse a modelos expulsados del centro de la literatura gallega para adultos ${ }^{2}$, o bien a modelos procedentes de otras literaturas, especialmente la castellana ${ }^{3}$.

En cuanto a la corriente predominante, el realismo crítico, se encontraba ya en Memorias dun neno labrego (Neira Vilas 1961), publicado en Buenos Aires y reeditado varias veces en Galicia desde 1968. Esta obra, no pensada inicialmente como LIJ, funcionó como obra ambivalente desde poco tiempo después de su publicación (Roig 1996). La obra alcanzó tal popularidad que se convirtió en una de las más leídas y vendidas de la literatura gallega. Fue auto-traducida al castellano (en 1974, en España reeditada en 1980 y 1987); traducida al catalán (1985), euskera (1988) y otras muchas lenguas. Aunque ninguna edición de las realizadas hasta 1980 se destinaba al público infantil y juvenil, la popularidad que estas proporcionaron a su autor, Neira Vilas, debió de ser el detonante de la traducción de una obra suya posterior, ya específicamente infantil, al catalán y al castellano. Se convierte, de esta manera, en el único escritor de la LIJ gallega que ve sus obras traducidas en el ámbito español durante el período analizado, a excepción de las coediciones.

Resulta significativo que solo gracias a una obra ambivalente se diera a conocer un autor de la LIJ gallega en el ámbito español (salvando la excepción de Xohana Torres 1967, cuyo libro era coeditado), lo que demuestra la falta de atención que recibía este sector en el exterior, por lo menos hasta el final del período analizado. Tampoco es casualidad que la obra canonizadora de Neira Vilas se insertara en la corriente del realismo crítico, tan en boga por aquellos años en algunas literaturas del entorno (Roig 1996), ni que las imágenes proyectadas de la cultura y la vida gallega (rural, caciquil, llena de miseria...) coincidieran con las predominantes por aquel entonces fuera de Galicia. La obra de Neira Vilas se aceptó, pues, como un texto costumbrista que se aproximaba a los gustos e imágenes difundidos en el ámbito español ${ }^{4}$. Mientras tanto, Casares tradujo y escribió, en la misma época que Neira Vilas, varias obras imaginativas y muy innovadoras para el sistema de LIJ gallega del momento, e incluso de todo el ámbito español (Neira Cruz 2004: 110). Hoy en día es un autor ya canonizado en la literatura gallega, sobre todo por su obra para adultos, pero sus textos de LIJ de los años 60 y 70 permanecen sin ser traducidos. La fantasía, en una etapa de predominio del realismo, y la ausencia del costumbrismo debieron de jugar en su contra frente a la posibilidad de ver traducidas sus obras.

Mientras tanto, los productores gallegos continuaban una lenta fase de formación del sistema en que la escasez de obras innovadoras se correspondía con la de traducciones. Esto evidencia sobre todo la escasa preocupación por la LIJ que tenían los productores gallegos tras el fracaso de las primeras traducciones, aunque también indica la intención nacionalista de transmitir a los niños sobre todo la tradición popular y las características más propias de la cultura gallega ${ }^{5}$. Así, hasta 1972 no aparece la primera traducción de esta etapa (de un texto de Saint-Exupéry), que es por primera vez en el período una traducción planificada de un clásico de LIJ publicada con posterioridad a su texto de origen. Esta obra gozó de tal acogida entre el público que fue reeditada dos veces durante los años 70 , y muchas más en el período posterior y hasta nuestros días. Casares realizó la traducción directa del francés. Aunque ya había cultivado la fantasía en su obra de 1968, la traducción del clásico le debió de dar a Casares nuevas ideas para

nenos se presenta en bicromía (salvo en las cubiertas) y en rústica. Este libro mantiene las características de la colección creada por Galaxia en 1967.

2 Por ejemplo, la poesía social que se hacía en los años 50 y 60 fue retomada por Manuel Ma Fernández en 1979 para los niños. En Roig (1996) se incluye también Un tempo de sol a sol (Poemas do neno galego) (Lueiro Rey 1974), pero no creo que el destinatario principal fuera el infantil en este caso.

${ }^{3}$ Por ejemplo, en el volumen bilingüe Rondas de norte a sur: poesía infantil Pura Vázquez utiliza para las composiciones gallegas el mismo modelo que para las castellanas, ya empleado anteriormente en 1952, en Columpio de luna a sol (poesía infantil) (Roig 1999: 13).

${ }^{4}$ La cubierta posterior de la traducción castellana resalta las técnicas tradicionales usadas por el autor y el valor de la obra como "documento histórico de primer orden".

${ }^{5}$ Roig (1996) señala la recopilación del pasado literario, junto con el didactismo y la crítica social, como característica propia de las "literaturas en proceso de descolonización", con el objetivo de salir de la dependencia cultural a que se ven sometidas. Las tres características se encuentran en esta etapa de la LIJ gallega. 
renovar otro género en la LIJ, puesto que en 1973 publica la pieza de teatro As laranxas máis laranxas de todas as laranxas.

El teatro infantil gallego se ve reforzado ese mismo año con una traducción del castellano publicada por la editorial Galaxia fuera de colección: Os anxos cómense crus (Díaz 1973). Esta obra, sin embargo, no se considera una traducción procedente del ámbito español, ya que con toda probabilidad su texto fuente no ha sido hasta ahora publicado, difundido ni escenificado en España ${ }^{6}$. $\mathrm{Su}$ autor, Jorge Díaz, es un dramaturgo chileno muy reconocido, que vivió en España durante treinta años a partir de 1965. El texto de partida, $E l$ día en que los ángeles se comieron a los pájaros de cu-cú fue escrita en 1966 desde Madrid, pero pensando en Ictus, el grupo chileno que la estrenó un año más tarde en Chile. Su primera edición se incluye en Díaz (1992). La traducción gallega se debe en este caso a la amistad personal que unía a Díaz con Daniel Cortezón, el dramaturgo gallego que llevó a cabo la traducción ${ }^{7}$. No se trata, en cualquier caso, de un hecho meramente fortuito, sino que la escasez de teatro infantil gallego debió de motivar tanto a Cortezón para efectuar la traducción como a Galaxia para publicarla.

En cuanto a la selección concreta de la pieza, la lengua castellana pudo haber sido un factor decisivo. Puesto que casi todos los productores de la LIJ gallega son bilingües, el castellano era una lengua muy accesible a la hora de ser traducida. No se escoge, sin embargo, una obra ya publicada, sino una que permanecía inédita a pesar de haber transcurrido ya siete años desde su creación, y a pesar de que varias obras de Díaz habían sido editadas en España, para niños o para adultos, en castellano o catalán. Se trata, por tanto, de una decisión deliberada que se podría poner en paralelo con la traducción del clásico de Antoniorrobles La bruja doña $P a z$, ya que también en este caso se manifiestan las relaciones constantes que mantiene el ámbito español con la literatura hispanoamericana.

Los productores gallegos, tanto en el caso de Galaxia como en el de Ediciós do Castro (que publicó la obra de Antoniorrobles), buscaron en la traducción de textos escritos en castellano pero no difundidos en España (o escasamente difundidos) la solución a las dificultades de desarrollo de una literatura periférica, emergente y dependiente. En los dos casos aludidos se consiguió una traducción que no había de competir en el mercado con sus textos de origen y que requería poca energía. Piénsese que incluso la obtención de los textos fuente debió de ser sencilla. Se buscaron así modelos propios para la LIJ gallega, no muy presentes en el resto del ámbito español, aunque fuera a través de la lengua central de dicho ámbito. Ambas traducciones se presentan explícitamente como tales, ya que la traducción era valorada en la literatura gallega del momento.

Sin embargo, en Díaz (1973) se refleja la preeminencia del texto en castellano, al que los lectores podrían atribuir un origen español debido a que el autor ya tenía otras obras publicadas en España. Me refiero a que el texto de partida de las canciones de esta pieza se puede leer en las partituras de la edición gallega, que añaden la traducción debajo de las anotaciones musicales. Se puede así comparar el texto castellano con su traducción al gallego, observando que el ritmo y la rima desaparecen en ocasiones en la redacción gallega, al realizar una traducción más o menos literal. Los productores gallegos no se preocuparon, pues, de las imágenes literarias que la traducción transmitía, dejando patente el predominio de la lengua castellana.

En cuanto a las aportaciones de esta traducción, se trata de una obra aislada en el conjunto de la LIJ gallega del momento: es probablemente la primera pieza de teatro musical en gallego, la primera traducción de literatura dramática infantil al gallego, y presenta un modelo repertorial (participación del público, ruptura de la lógica del mundo real...) alejado de los presentes en la LIJ gallega editada hasta la fecha: el teatro de marionetas propuesto por Manuel $\mathrm{M}^{\mathrm{a}}$ Fernández y las breves piezas costumbristas y sentimentales escritas por Dora Vázquez. La obra de Casares, premiada poco antes de salir a la luz la obra de Díaz (1973) ${ }^{8}$, es más similar en la ruptura de la lógica convencional, aunque las diferencias entre ambas obras son notables. Podemos suponer, pues, que la novedad repertorial de Díaz (1973) tuvo mucho que ver en su selección, tenien-

\footnotetext{
${ }^{6}$ En los archivos del Centro Nacional de Documentación Teatral, con datos exhaustivos desde 1985, no consta ninguna representación de la obra. Anteriormente la pieza no había sido editada y el escritor desconoce cualquier posible representación.

${ }^{7}$ Estas declaraciones fueron realizadas por el propio escritor a través de un correo electrónico del 17 feb. 2006.

8 La pieza de Casares ganó el premio O Facho en 1973, fallado el 17 de mayo, mientras que el colofón de Os anxos cómense crus señala el mes de junio del mismo año como fecha en que se acaba de imprimir la edición.
} 
do en cuenta además la importancia que se atribuye al teatro en la cultura gallega en general. Tal vez había también en esta iniciativa un intento de fomentar un tipo de teatro infantil más innovador, como el propuesto por Casares. La recepción de ambas obras, sin embargo, es muy diferente. Por una parte, la obra de Casares fue representada varias veces en el mismo año de su publicación y se ha recuperado recientemente. Por su parte, $O s$ anxos cómense crus fue estrenada por el grupo gallego Tespis en las muestras de teatro de Ribadavia, en 1975 , pero no hay noticia de representaciones posteriores ni reivindicaciones de la obra, por lo que parece haber caído en el olvido. Así pues, la preferencia por los autores gallegos se manifiesta a pesar de aquellos que constantemente reivindican más traducciones en la literatura gallega.

En los años posteriores a la obra de Díaz (1973) se retoman en la LIJ gallega algunos de sus elementos: por ejemplo el uso de las canciones en Teatro de todo o ano (Babarro 1978) y Ronseles. Teatro infantil galego (Pura y Dora Vázquez 1980), o la participación del público en Sinfarainín contra don Perfeuto (Graña 1975), O xigante Don Gandulfo Señor de Tentequedo (aquí mucho menos funcional: Pisón 1980) y Ronseles. En la primera obra mencionada y en "Xuicio no bosque ou soñar non costa nada" de Ronseles, una de las funciones del público es idéntica a la de Os anxos cómense crus: emitir un veredicto (culpable o inocente) con respecto a los personajes ${ }^{9}$.

A pesar de la singularidad de la obra de Díaz (1973), en fin, podemos insertar la traducción en la política editorial gallega del momento, con respecto a las piezas dramáticas para adultos:

Por estes anos abondan -a abondancia sempre é relativa nestes casos- as traducións [...] Tradúcese de todo, clásico e contemporáneo, na ilusión de que un día o teatro galego poderá inscribirse na cultura universal. Tradúcese e publícase desordenadamente, sen temor ao caos. En Galicia non hai grupos que monten esas obras. Tampouco hai autores, e a tradición teatral pódese decir que está esquencida. As traducións veñen encher ese espacio valeiro, a suscitar un interés polo teatro moderno en galego. Ese vai ser, pois, logo, a función das traducións: o potenciar un teatro autóctono á altura dos tempos. (Lourenzo 1999: 133-134)
Otra pieza teatral para niños fue Monicreques: teatro infantil galego, obra auto-traducida por las gallegas Pura y Dora Vázquez (1974). Con este libro se introduce el teatro escolar en la LIJ gallega, aunque ya se encontraba en las literaturas vecinas.

En 1973 se publica Mar adiante (historias de nenos pra nenos) de Moreno, obra narrativa gallega en que se combina la tradición propia (las costumbres y forma de vida de un pueblo marinero) con las ideas de renovación pedagógica que enlazan con las presentes en otras obras catalanas del momento. Ambos componentes se encontraban ya en el libro de Xohana Torres, aunque Moreno les da un tratamiento diferente y los presenta en un modelo de narración más extensa.

Desde 1975, año en que finaliza la dictadura franquista, algunos libros de LIJ gallega, no traducidos a ni de otras lenguas, se editan fuera de Galicia. Comienza así la intervención de las editoriales foráneas en la LIJ gallega, aunque de manera reducida por el momento. Desde Madrid, Akal publica varias obras de Neira Vilas, que se encontraba exiliado en Hispanoamérica. Entre estas obras cabe destacar la que comparte con Miranda, ya que contiene dos cuentos auto-traducidos que se habían publicado en una revista infantil de Cuba, donde vivía la pareja de autores. La relación personal entre los dos escritores provocó la publicación conjunta.

En Madrid se edita también en 1975 (Marín y Patiño 1975) el primer álbum gallego de cómic para jóvenes, aunque en una editorial gallega establecida en Madrid. Este libro debió de incentivar la traducción de una de las series de cómics, para niños y jóvenes de diferentes edades, más famosas de aquella época y de todos los tiempos: "Astérix". La traducción refuerza así la presencia del cómic en la LIJ gallega, aunque el género fue introducido por una obra autóctona. Constituye esta la segunda vez, tras Os anxos cómense crus, que las creaciones propias estimulan las traducciones en la LIJ gallega. El mayor coste de una traducción no motivaba a los editores a publicarla y normalmente preferían promocionar a los autores gallegos aun a riesgo de una escasa renovación del repertorio. Solo cuando el modelo ya existe se refuerza con traducciones que lo afianzan.

La serie de Astérix fue publicada en gallego, por iniciativa de la librería Arenas de A Coruña. Se

\footnotetext{
9 Ya en Contos que van prá feira: tres sainetes (Cacheda 1962) el público debía emitir un veredicto final, pero con respecto a la representación y no a los personajes.
} 
publicaron cuatro volúmenes en 1976, dos en 1977 y otros dos en 1978. Se trata, por tanto, de la primera serie de LIJ traducida al gallego, lo cual supone una aportación mayor en cantidad de volúmenes que en innovaciones repertoriales, ya que todos estos libros presentan un mismo modelo. Por otra parte, las traducciones eran realizadas a través del texto puente castellano, por lo que se mantenía el vínculo y la dependencia de la literatura central del ámbito español, tanto en los modelos propuestos como en la selección concreta de títulos. La sintaxis se mantiene bastante próxima a la castellana, mientras que el léxico se pretende diferencial.

Paralelamente a estas traducciones, en la revista Vagalume (1975-1978) se publicaban cómics de breve extensión, primero de creación gallega y posteriormente traducidos, sobre todo del catalán. El álbum de cómic infantil gallego, sin embargo, careció de continuidad, tal vez debido a la debilidad de la industria editorial. Hasta el final del período solo se publicó Gaspariño (Marín 1978).

También se traducen en 1976 dos piezas teatrales del indio Rabindranath Tagore, recogidas en un solo volumen. Continúa así la traducción de obras dramáticas de diferentes orígenes, que en este caso se resalta mediante la utilización de antropónimos y otras palabras indias. Los paratextos del volumen no se dirigen con evidencia al lectorado infantil y juvenil, aunque las características de la primera pieza se ajustan bastante a lo que se cree adecuado para este tipo de receptor: protagonista infantil, paralelismo en las secuencias, sencillez aparente...

Se agota así la lista de LIJ gallega traducida hasta 1978, año en que aparte de la serie de Astérix se publican dos títulos más. Uno de ellos es la traducción de un álbum ilustrado catalán (Escuela Roure-Mallorca 1978); el otro es la reedición facsímil de la única traducción gallega para niños y jóvenes anterior a la Guerra Civil: Os catro cisnes brancos: lenda celta (Chisholm 1978). Se trata, por tanto, de una edición motivada ideológicamente y de gran relevancia histórica para la LIJ gallega. Los paratextos, en cambio (pequeño formato, ausencia de ilustraciones y de color), están ya muy alejados de los que presentan las traducciones de este período e incluso de las creaciones gallegas de los años anteriores. En cuanto al modelo narrativo, supone un antecedente de las leyendas y cuentos populares que serán traducidos en los años siguientes, si bien la literatura de tipo tradicional no se había dejado de editar nunca en el polisistema gallego.

\section{CONCLUSIONES}

Durante la etapa analizada se forma un corpus de obras específicas que permite hablar de un incipiente sistema de LIJ gallega, si bien sus límites con la literatura para adultos son todavía difusos y la estratificación prácticamente inexistente. Tampoco se daba la planificación, sino que las publicaciones de las diferentes obras parecen iniciativas inconexas. Algunos títulos se pueden relacionar con otros, como ocurre con las colecciones, pero las iniciativas carecían siempre de continuidad, normalmente debido al fracaso comercial de las publicaciones anteriores. De ahí que el número de reediciones fuera muy bajo: cinco de obras autóctonas y tres de traducciones.

La ausencia de planificación no significa que no se siguieran unas tendencias particulares, como el predominio de las creaciones autóctonas sobre las traducciones o la preponderancia entre las primeras de la corriente del realismo crítico.

Las traducciones constituyen el $26 \%$ de la producción. En los años anteriores habían sido las pioneras de la LIJ, pero su fracaso de ventas desanimó a los editores. El éxito de la siguiente traducción realizada (Saint-Exupéry 1972) animó a los productores del polisistema a publicar nuevas traducciones, aunque en cantidades muy reducidas. En total, nueve traducciones del francés, dos del castellano (aunque una de ellas procede de la literatura hispanoamericana), una del catalán y una reedición de una traducción del inglés. Se observa así que se traducen sobre todo las lenguas de prestigio por aquel entonces (francés, castellano, inglés), si bien estos datos deben ser matizados.

Por una parte, la traducción en bloque de la serie "Astérix" hace que la presencia de las obras franco-belgas sea mucho mayor de lo que cabría esperar. Si tenemos en cuenta que estas traducciones fueron realizadas desde el texto puente castellano el panorama varía considerablemente, ya que presenta de nuevo el dominio de la literatura central del ámbito español en las traducciones a los polisistemas periféricos. Solo Casares tradujo el texto de Saint-Exupéry directamente desde su fuente durante estos años. Por otra parte, la lengua inglesa representa aquí la literatura irlandesa, mucho más periférica que la anglosajona o la norteamericana. La importancia de la ideología nacionalista por estos años erige la literatura irlandesa como modelo para la gallega, aunque ya con menor relevancia de la que tenía en el período anterior a la Guerra Civil Española. En tercer 
lugar, una de las traducciones realizadas del castellano corresponde a la literatura chilena. Se puede decir, por tanto, que muchas de las traducciones realizadas durante este período tienen su origen en lenguas prestigiosas, pero vehiculando literaturas más o menos periféricas. Así pues, los productores gallegos no buscaron durante estos años maneras de aproximarse a las literaturas del ámbito español a través de las traducciones, sino que intentaron formar su propio sistema de LIJ con creaciones autóctonas y algunas traducciones procedentes del exterior del ámbito español. De hecho, en muchas ocasiones las traducciones sirvieron más para reforzar modelos ya introducidos por alguna obra gallega esporádica que para introducir nuevos modelos en el repertorio. La escasa energía de un sistema periférico en una literatura periférica, sin embargo, hizo que la dependencia de la literatura castellana continuara mediante las traducciones indirectas a través del texto puente castellano, o mediante la selección de un texto de partida cuya lengua es la utilizada por la literatura central del ámbito español. Solo dos traducciones se realizan directamente de una lengua distinta del castellano, pero una de ellas es en realidad la reedición de una obra publicada en el período anterior.

En general, por aquellos años la repercusión era mayor en los polisistemas de partida que en el gallego, debido tanto al precario desarrollo del mercado de LIJ gallego como a la preferencia en este por los autores autóctonos. La crítica gallega solía ser buena al valorar la contribución que hacían las traducciones a la normalización lingüística y literaria, pero hasta los últimos años del período apenas llegaron estas obras al público en general. De hecho, la ausencia casi total de reediciones de las traducciones al gallego aquí presentadas señala que estas obtuvieron una acogida entre el público menos favorable que la de obras gallegas autóctonas. La preferencia por la lectura en castellano (que con frecuencia permitía acceder a las mismas obras) y por los autores gallegos, por parte de una minoría nacionalista, explican este hecho.

Por contraste, son varias las obras gallegas autóctonas reeditadas ya durante el período estudiado, muchas de ellas recuperadas a finales del siglo XX y principios del XXI. La preocupación por las obras propias, pues, está aumentando mientras que las traducciones del ámbito español, a pesar del importante papel que jugaron en la conformación del sistema de LIJ gallega, permanecen relegadas en el olvido.

Un ejemplo lo constituye Os anxos cómense crus. Se trata de una pieza singular que se puede relacionar con otras obras de la literatura gallega: con As laranxas máis laranxas de todas as laranxas por el uso de la fantasía frente al realismo crítico predominante, con la tendencia a traducir obras en castellano no difundidas en Galicia y con la tendencia a traducir piezas teatrales de cualquier tipo, aunque no tengan nada que ver con las publicaciones anteriores. También esta pieza, como muchas otras de aquel período, tuvo su repercusión en la LIJ gallega introduciendo nuevos modelos que luego se retomarían en las obras autóctonas; y como muchas otras, se encuentra hoy relegada al olvido. 


\section{BIBLIOGRAFÍA}

Antoniorrobles (1980): A meiga dona Paz. Ilust. Karawane. Trad. Claudio González Pérez. Sada (A Coruña): do Castro.

BABARro, Xoán (1978): Teatro de todo o ano. Cuadernos da Escola Dramática Galega, no 3. A Coruña: Escola Dramática Galega.

CACHEDA, Edelmira (1962): Contos que van prá feira: tres sainetes. Santiago de Compostela: autora-editora.

Candel Tortajada, Francisco (1967): Unha nova terra. Ilust. Cesc. Trad. Xohana Torres Fernández. Vigo: Galaxia/Barcelona: La Galera.

CASARes Mouriño, Carlos (1973): As laranxas máis laranxas de todas as laranxas. Ilust. Luís Seoane. Vigo: Galaxia.

Chisholm, Loney (1978): Os catro cisnes brancos: lenda celta. 1922. Trad. Manoel Fernández Barreiro. A Coruña: do Rueiro/La Voz de Galicia.

Cots Moner, Jordi (1966): O abeto valente. Ilust. Maria Rius. Trad. Xohana Torres Fernández. Vigo: Galaxia/Barcelona: La Galera.

DíAz, Jorge (1973): Os anxos cómense crus. Trad. Daniel Cortezón. Vigo: Galaxia.

- (1992): Teatro para niños. Santiago de Chile: Emisión.

Domínguez PÉREZ, Mónica (2008): “As primeiras traducións de literatura infantil e xuvenil ao galego: normas de tradución, difusión e recepción", en Boletín Galego de Literatura, n ${ }^{\circ} 39-40$. Santiago de Compostela: Universidade de Santiago de Compostela, pp. 37-60.

Escuela Roure-Mallorca. Colectivo Pedagógico de Padres y Maestros (Barcelona) (1978): Ona e Ori: un dia na escola. Ilust. Montserrat Tobella Soler. Barcelona: 7 1⁄2.

Even-Zohar, Itamar (1990): "Polysystem Studies", en Poetics Today, n 11/1. Tel Aviv: Tel Aviv University.

FERNÁNDEZ, Manuel Ma (1989): Barriga verde: farsa pra bonecos. Vigo: Castrelos.

FERnÁndez PAZ, Agustín (1989): Os libros infantís galegos. Santiago de Compostela: Consellería de Cultura e Deportes da Xunta de Galicia.

GraÑA, Bernardino (1975): Sinfarainín contra don Perfeuto. Separata de Grial, $\mathrm{n}^{\circ}$ 48. Vigo: Galaxia.

Lourenzo, Manuel (1999): O Teatro galego contemporáneo (1936-1996). A Coruña: Biblioteca-Arquivo Teatral "Francisco Pillado Mayor".

Lueiro Rey, Manuel (1974): Un tempo de sol a sol (Poemas do neno galego). A Coruña: Moret.

MARÍN, Xaquín (1978): Gaspariño. A Coruña: do Rueiro.

MARín, Xaquín y Reimundo PATiÑo (1975): 2 viaxes. Ilust. Xaquín Marín y Reimundo Patiño. Madrid: Brais Pinto.

MARTín, Paco, et al. (1979): Contos pra nenos. Ilust. Xosé M. Xiraldez. Vigo: Galaxia.

Moreno, Ma Victoria (1973): Mar adiante (historias de nenos pra nenos). Ilust. Araceli Liste. Sada (A Coruña): do Castro.

- (1989): El penell. Ilust. Carmen Peris. Barcelona: Abadia de Montserrat.

NeIRA CRUZ, José Antonio (2004), "105 anos de literatura infantil e xuvenil en galego", en Grial, n 161. Vigo: Galaxia, pp. 107-113.

NeIRA Vilas, Xosé (1961): Memorias dun neno labrego. Ilust. Isaac Díaz. Buenos Aires: Follas Novas. [Primera edición en España, Sada (A Coruña): do Castro, 1968]. [Trad. al castellano, Memorias de un niño campesino. Madrid: Júcar, 1974]. [Trad. al catalán, Memòries d'un nen de pagès. Trad. Marc Ferrer. Barcelona: Juan Granica, 1985]. [Trad. al euskera, Mutiko baserritar baten oroitzapenak. Trad. Andrés Urrutia. Bilbao: Labayru Ikastegia, 1988].

Neira Vilas, Xosé, y Anisia Miranda (1975): Cantarolas e contos pra xente miúda. Madrid: Akal.

Pisón, Xesús (1980): Oxigante Don Gandulfo Señor de Tentequedo. Cuadernos da Escola dramática galega, $\mathrm{n}^{\circ}$ 13. A Coruña: Escola Dramática Galega.

PRIETO, Laureano (1968): Contos pra nenos. Vigo: Galaxia.

Roig Rechou, Blanca-Ana (1996): A Literatura galega infantil: perspectiva diacrónica, descrición e análise da actualidade. Santiago de Compostela: Servicio de Publicacións e Intercambio Científico da Universidade de Santiago de Compostela. [Microforma]. 
(1999): "Pura e Dora Vázquez, dúas mestras na literatura infantil galega", Fadamorgana, no 2. Santiago de Compostela: Atlántica de Información e Comunicación de Galicia, pp. 12-16.

- (2006): "Ramón Piñeiro e a literatura infantil", Encontro Ramón Piñeiro. Coord. Charo Ferreiro e Inmaculada Pena. Santiago de Compostela: Consellaría de Cultura e Deporte da Xunta de Galicia, pp. 29-39.

SAINT-EXUPÉRY, Antoine de (1972) : O Principiño. Ilust. Antoine de Saint-Exupéry. Trad. Carlos Casares Mouriño. Vigo: Galaxia.

ToRres FERnÁNDEZ, Xohana (1967): Polo mar van as sardiñas. Ilust. Ismael Balanyà Moix. Barcelona: La Galera/Vigo: Galaxia.

VÁZQUEZ, Dora (1973): Tres cadros de teatro galego. Ourense: La Región.

VÁZQuEZ, Pura (1952): Columpio de luna a sol (poesía infantil). Ilust. Zaragüeta. Madrid: Boris Bureba. (1968): Rondas de norte a sur: poesía infantil. Ilust. Jaime Quesada. Ourense: Caixa de Aforros de Ourense.

VÁzQuez, Pura y Dora (1974): Monicreques: teatro infantil galego. Trad. Dora y Pura Vázquez. Ourense: La Región. [Incluido en: Teatro completo para nenos. Ourense: Abano, 2000]. - (1980): Ronseles. Teatro infantil galego. Ourense: La Región. 